
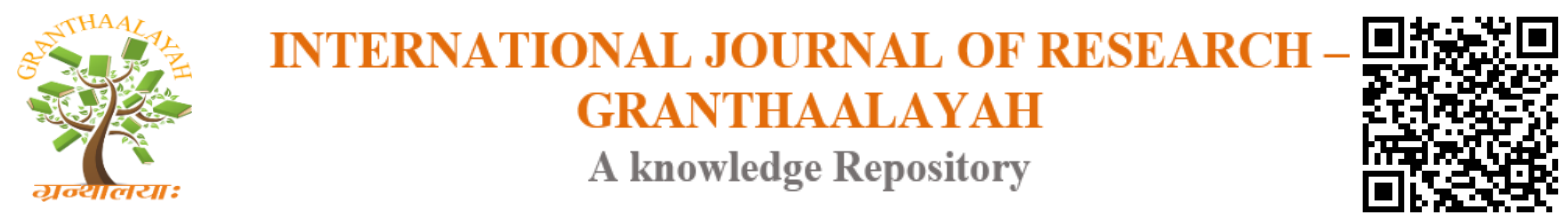

Science

\title{
INVESTIGATION AND ANALYSIS OF POWER QUALITY OF SINGLE PHASE, LOW VOLTAGE CONSUMERS IN ADO -EKITI METROPOLIS
}

\author{
P.K. Olulope ${ }^{1}$, O.S.Adeoye ${ }^{2}$ \\ ${ }^{1,2}$ Department of Electrical and Electronic Engineering, Faculty of Engineering, Ekiti State \\ University, Ado-Ekiti, Nigeria
}

\begin{abstract}
This paper examines the power quality of Ado-Ekiti metropolis in Ekiti State, Nigeria. The metrics of power quality includes: disturbances such as interruptions, voltage sags, spikes and momentary losses, power harmonics, and voltage unbalances with intrinsic effects on the efficiency and performances on the electric equipment. The necessity for this paper is the fluctuations of voltage supplied to the consumers by the distribution company in Ekiti State. These have significant effects on the power delivered to consumers 'appliances, quality of their lives and the development of the society at large. The quality of voltage of each consumer in the selected areas were measured with the aid of digital multimeter which was compared with the standard nominal voltage of $240 \mathrm{~V}$, voltage deviations were evaluated through the use of standard mathematical equation and linear regression model was employed on the calculated voltage deviation with day and time used as inputs and the voltage deviation as the output. The implementation of the modelling was achieved through the use of Microsoft Excel data tool. The power quality for areas 1, 2, 3 for the hours under consideration were poor with respect to R2 range of above 0.5 but better than that area 4 with R2 value of less than 0.5 .The results were compared and recommendations were made with the view of improving the power quality in the metropolis.
\end{abstract}

Keywords: Power; Consumers; Quality; Ekiti; Harmonic; Voltage; Regression Method; Digital Multi Meter.

Cite This Article: P.K. Olulope, and O.S.Adeoye. (2018). "INVESTIGATION AND ANALYSIS OF POWER QUALITY OF SINGLE PHASE, LOW VOLTAGE CONSUMERS IN ADO -EKITI METROPOLIS." International Journal of Research - Granthaalayah, 6(5), 177-189. https://doi.org/10.29121/granthaalayah.v6.i5.2018.1439.

\section{Introduction}

Minimal attention has been given to power quality in the developing nations in which Nigeria is not left out. In the developed countries like United Kingdom, United States of America, Ukraine, Japan, Canada and others, the situation is different because they attach great importance to good power quality and more importantly its economic implication. The reasons for its importance are: 
delivery of voltages and currents within the standard voltage deviation of $6 \%$ at the distribution level [1]. Electric power efficiency is defined as a condition of its consumption that ensures the availability of required quality of electrical energy while maximum production losses will have been inherent to the process [2]. A transmission line is not subjected to such restriction and its voltage can vary as much as $10 \%$ to $15 \%$ due to variation in loads [3]. Electrical supply must continuously match load demand at all times so as to ensure power balance of the network. It is a fact that load on power network varies from time to time due to the behaviour of Consumers that is unpredictable [1]. This makes it difficult to control and maintain power quality. Disturbances such as momentary voltage sags and spikes, power harmonics and voltage unbalances are intrinsic characteristics of electricity with direct impact on efficiency and performance of the electric equipment[4]. In Ado-Ekiti metropolis, the residents have not been enjoying constant power supply and good power quality because, the power authority (Benin Electricity Distribution Company) inherited problems from Power Holding Company of Nigeria (PHCN) ranging from Planning, inadequate kVA rating of transformers, illegal connections, in-adequate cross sectional areas of aluminum conductors, unnecessary long span of conductors, insufficient injected power from the authority to the community. Power quality should be given great attention in order to improve efficiency and life span of electrical appliances in our homes and reduce economic loss on the part of the consumers and the power authorities. It has been impossible for the Ado Ekiti residents to enjoy good power quality because the power supply is not constant due to outages (interruptions), the applied voltage is lower to or above acceptable voltage level, the power system frequency is fluctuating and the current and voltage sinusoidal waveform of the supply is distorted [5]. Power quality is the combination of voltage quality and current quality. Quality of supply is a combination of voltage quality and the non-technical aspects of the interaction from the power network to its customers. Voltage quality is concerned with deviations of the voltage from ideal. The ideal voltage is a single frequency sine wave of constant amplitude and frequency. Current quality is the complementary term to voltage quality. It is concerned with the deviation of the current from the ideal. The ideal current is again a single frequency sine wave of constant amplitude and frequency with the additional requirement that the current sine wave is in phase with the voltage sine wave [6]. Power quality is a simple term which describes a multitude of issues that are found in any electrical power system and is a subjective term. The concept good and bad power quality depends on the end users. If a piece of equipment functions satisfactorily, the end user feels that the power is good. If the equipment does not function as intended or fails prematurely, the feeling is that the power is bad [7].If the power quality of the network is good, then any load connected to it will run satisfactorily and efficiently. This will reduce the running costs and carbon footprint. When the power quality is poor, then, the loads connected to it will fail or will have a reduced lifetime, and the efficiency of the electrical installation will reduce. The following main contributors to low voltage poor power quality can be defined as: reactive power, as it loads up the supply system unnecessary; harmonic pollution, as it causes extra stress on the networks and makes installations run less efficiently; load imbalance, especially in office building applications, as the unbalanced loads may result in excessive voltage imbalance causing stress on other loads connected to the same network and leading to an increase of neutral current and neutral to earth voltage build up and fast voltage variations leading to flickers [8]. Causes of harmonics are usually non-linear electric loads which include the use of Uninterruptible Power Supply , rectifiers, inverters, variable drives, arc furnace welding machines, voltage controller and frequency converters [5].There are different ways to enhance power quality problems in transmission and distribution systems. Among these are the D-STATCOM which an effective 
device. A pulse width modulation control scheme has been implemented to control the electronic valves [9]. It was posited in Europe that on the average, the absolute share of impacts of power quality and reliability related problems are due to voltage dips (23.6\%), short interruptions (18.8\%), long interruptions (12.5\%), harmonics (5.4\%), transients and surges $(29 \%)$ and other power quality related problems (10.7\%) [10]. A voltage generator provides controlled voltage into the grid which ensures nominal voltage to the load even during grid disturbances such as network unbalances, flickers and voltage dips. It has impact on improvement of power quality which are usually installed at the beginning of a distribution feeder or before a group of loads [11].

\section{Background of the Study}

\section{Metrics of Power Quality}

Most typical indices for measuring power quality disturbances are known as the metrics which are listed below:

i. Distortion factor: The ratio of the root square value of the harmonic content to the square root value of the fundamental quantity expressed as a percentage of the fundamental is known as total harmonic distortion (THD) as stated in equation 1.

$\sqrt{\frac{\sum_{h=2}^{n} V_{n}^{2}}{V_{1}^{2}}} \times 100 \%$

ii. Crest factor: The ratio of the peak value of a periodic function to the peak value of aperiodic function to the root mean square value i.e crest factor (Cf) as stated in equation 2

$\mathrm{C}_{\mathrm{f}}=\frac{y_{\text {peak }}}{y_{r . m . s}}$

$\mathrm{y}_{\text {peak }}$ is the value of a periodic function, $\mathrm{y}_{\text {r.m.s }}$ is the root mean square value of the aperiodic function.

iii. Notch area: A notch in the power system voltage (or current):

A notch area is defined as: $A n=t . d$

An is the notch area in volt micro second, $t$ is the notch time duration in microseconds, $\mathrm{d}$ is the notch depth in volts as stated in equation 3

iv. Recovery time: This is the time needed for the output voltage or current to return to a value within the regulation specification after a step load or line change.

v. Displacement power factor: This is the active power of the fundamental wave, in watts, to the apparent power of the fundamental wave in volt amperes.

vi. Total power factor: The ratio of the input in watts, to the total volt ampere input. This includes the effect of harmonics.

vii. K factor: A measure of transformer's ability to serve non sinusoidal loads. The $\mathrm{K}$ factor is defined as stated in equation 4

$K=\sum_{h=1}^{h_{\max }} I_{P U}^{2} h^{2}$ 
$\mathrm{I}$ is the harmonic component at $\mathrm{h}$ times the fundamental frequency and $\mathrm{h}$ is the harmonic order of I in multiple of fundamental frequency.

i. Non linear loads: Loads are known as demand and it is defined as the amount of electrical energy consumed over time. In the past, most loads were linear, that is, the load impedance remains constant regardless of the applied voltage. Expanded markets of computers, uninterruptible power supplies and variable speed motor drives resulting into non linear waveforms are drastically different. Measuring non sinusoidal voltage and current waveforms require a true R.M.S meter. Conventional meters usually measure average value of amplitude of a waveform.

ii. Electrical Harmonic: Power quality now relates to short term transients as well as continuous state distortions. Harmonics can be present in current, voltage or both. $60 \%$ of all electrical devices operate with non- linear current drawn. Harmonic distortion can cause serious problems for the users of electric power, from inadvertent tripping of circuit breakers to dangerous overheating of transformers and neutral conductors as well as heating motors and capacitor failure. A harmonic may be defined as an integer multiple of a fundamental frequency. Loads which produce harmonic currents include: electronic lighting ballasts, adjustable speed drives, personal computers, electric welding equipment, solid state rectifiers, saturated transformers, solid state elevator control and medical equipment. Harmonic in the electric power system combine with the fundamental frequency to create distortion. The contribution of all harmonic frequency currents to the fundamental current is known as total harmonic distortion (THD). THD is calculated as the square root of the sum of the square of all the harmonics divided by fundamental signals $(50 \mathrm{~Hz}$ or $60 \mathrm{~Hz}$ ). The equations 5, 6 and 7 represent total harmonic distortion, total harmonic distortion for current and voltage respectively.

\section{iii. Total Harmonic Distortion:}

$\% T H D=\sqrt{\frac{\text { sum of squares of amplitude of all harmonic }}{\text { square of amplitude of fundamental }}} \times 100 \%$

$\% \operatorname{THD}($ current $)=\sqrt{\frac{I_{2}^{2}+I_{3}^{2}+I_{4}^{2}+I_{5}^{2}}{I_{r m s}^{2}}} \times 100 \%$

$\% \operatorname{THD}($ voltage $)=\sqrt{\frac{V_{2}^{2}+V_{3}^{2}+V_{4}^{2}+V_{5}^{2}}{V_{1}^{2}}} \times 100 \%$

Power quality monitoring can be used proactively to prevent damage and system outages or after the fact as a form of analysis to isolate problem areas and identify solutions. Use of permanently installed power quality meters and power quality data logger such as Acuuim II W allows building Managers to remain proactive about power quality issue and avoid costly issues.

Several components can be measured individually for an in-depth analysis of the overall power quality. These are: transient voltages and currents, individual wave capture, harmonic distortion, sag and swell monitoring, frequency variations and power factors. 
iv. Voltage sags are referred to as voltage dips. IEE defines voltage sag as a reduction in voltage for a short time. The duration of voltage sag is less than 60 seconds but more than 8 milli second ( 0.5 cycle). The magnitude of reduction is between $10 \%$ and $90 \%$ of the normal root mean square (r.m.s) voltage at $50 \mathrm{~Hz}$ or $60 \mathrm{~Hz}$ [12].

v. Voltage swells or momentary over-voltages are r.m.s voltage variation that exceeds $110 \%$ of the nominal voltage and last for less than 60 seconds. It occurs less frequently than voltage sags. Single line to ground faults cause voltage swells. Long duration over-voltages are close cousins to voltage swells except they last longer like voltage swells, they are r.m.s voltage variations that exceed $110 \%$ of the nominal voltage. Unlike swells, they last longer than 60 seconds.

Interruption: It is a complete loss of voltage in one or more phases as stated in equation 8.

$V_{T H D}=\sqrt{\frac{\sum_{h=2}^{50} V}{V_{1}}}=\sqrt{\frac{V_{2}^{2}}{V_{1}^{2}}+\frac{V_{3}^{2}}{V_{1}^{2}}+\frac{V_{4}^{2}}{V_{1}^{2}}+\frac{V_{n}^{2}}{V_{1}^{2}}}$

The voltage levels in Ado-Ekiti are: $132 \mathrm{kV}$ for transmission level, $33 \mathrm{kV}$ for primary distribution, $11 \mathrm{kV}$ for secondary distribution, $415 \mathrm{~V}$ for three phase consumers, and $240 \mathrm{~V}$ for single phase consumers [13]. The quality concern is with deviations of voltage and frequency from ideal. The quality of power delivered to the Nigerian populace is characterised by voltage fluctuations, flickers, harmonics, dips, and swells. The problems need to be addressed to ensure safe, reliable and the right quality of electricity services [14].

\section{Methodology}

The method that will be used in this study involves measurements of voltages from the supply mains of each building in the Ado-Ekiti metropolis. The measurements will be carried out at a three hour interval for one week $(6,9,12,15,18$ and 24 hours of each day). The voltages are to be measured by digital multi meter in volts. Measurements of the voltages at the supply mains of the buildings of consumers which will be compared to the nominal voltage of $240 \mathrm{~V}$ using linear regression model. The determination of voltage deviation by the use of standard mathematical equation as stated in equation 9. The total harmonic distortion can be used to characterise distortion in voltage wave. The voltage harmonic distortions for third, fifth and seventh orders will be calculated by equation 10 .

Voltage deviation, $U_{\text {dev }}=\frac{U_{\text {nom }}-U_{\text {measd }}}{U_{\text {measd }}}$

$U_{T H D}=3 f_{0}, 5 f_{0}, 7 f_{0} \ldots \ldots \ldots \ldots \ldots f_{0}$

\section{Study Area}

Power quality of four different areas in Ado-Ekiti metropolis was investigated and analysed. The voltage from supply mains were measured from different buildings in the metropolis. The areas were Omisanjana, Federal Polytechnic, Olujoda, and Ekute. Omisanjana is basically a residential domain in Ado-Ekiti, a commercial nerve of the city and fast growing area particularly for residential purpose and commercial activities with $11 \mathrm{kV}$ powered transformers. Federal 
Polytechnic is one of the institutions in Ado-Ekiti which purely an academic environment powered by $11 \mathrm{kV}$ transformers. This is made up of Students Hostels, commercial buildings and Staff offices and Quarters. Olujoda is an area with one of the oldest Hotels in the city, fast growing and residential as well as commercial area. Ekute is one of the commercial centres of the city, a residential base and a modern area with all social amenities in the city. Voltages were measured in the areas at an interval of three hours for seven days. Digital multi-meters were used to measure the voltages at such intervals and recorded. Simple mathematical model (linear regression) was used to determine the voltage deviations.

\section{Results and Discussion}

Power quality of four different areas in Ado-Ekiti metropolis was investigated and analysed. The map of Ekiti State is shown in fig. 1 which shows all the sixteen local government areas including Ado-Ekiti metropolis. From each reading, values of voltage deviation were selected for different days with different time as shown in Tables 1, 2, 3, 4, 5, 6, 7 and 8. Therefore, the linear regression model was used for modelling equations for the four areas. The inputs were day and measured voltage while the time is a variable. During the process of analysis with MS-Excel data tool, it was observed that the input of day has no effect on the output. However, the effect of the day will be obvious over a long period of time particularly when different seasons of the year are under consideration which could be, rainy and dry seasons. From the hours of six to twelve, the behaviour of the voltage deviation complied with linear downward trend while from fifteen to twenty-four depicted a sinusoidal waveform. This paper therefore addresses from the hours of six to twelve that complies with linear downward trend using linear regression modeling with the help of micro soft excel data tool. This is with a view of proffering solutions to the sinusoidal waveform in the future from 15th hour to the 24th hour in the future with another model. For Vd1, the R2 is 0.9999 with an intercept of 0.1931 while the coefficient of deviation is -0.0037 . The $\mathrm{R} 2$ for $\mathrm{Vd} 2$ is 0.9761 ; the coefficient of deviation is 0.1126 while the intercept is -0.4743 . The $\mathrm{R} 2$ for $\mathrm{Vd} 3$ is 0.9316 ; the coefficient of deviation is 0.0082 while the intercept is -0.0445 . The $\mathrm{R} 2$ for $\mathrm{Vd} 4$ is 0.4475 , the coefficient of deviation is -0.0117 while the intercept is 0.3809 . It is important to note that the R2 is good when it ranges from 0.5 to 1.0 while any value less than 0.5 is poor. This shows that the use of linear regression model has aided in determining that the R2 for fourth area is poor while others are very good. It is good to

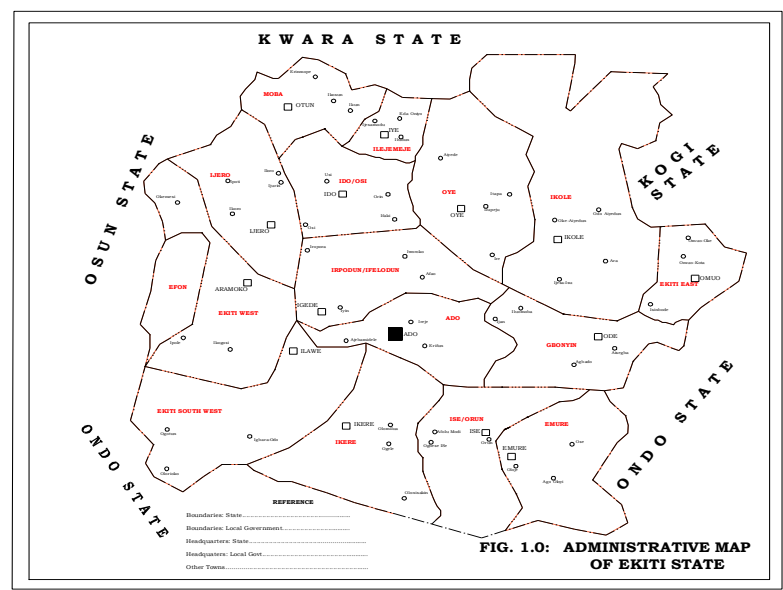


Note that the third, fifth and seventh harmonics in the areas are $150 \mathrm{HZ}, 250 \mathrm{~Hz}$ and $350 \mathrm{~Hz}$ thereby shifting the sinusoidal waves from the normal sine wave in accordance to the equation 2.The regression output for 0 to 24 hours was 0.91143 as shown in Table 11 . The square of the regression from the same table was 0.83070 and the intercept was 0.23 . Table 12 shows regression of 0.3804 , square of regression of 0.1447 and intercept of 0.1668 . The waveforms shown in fig. 2 is in deviance with fig. 3 and fig. 4 . This paper has contributed immensely to data bank of electrical power quality. The paper has shown the comparative analysis of the nominal voltage and the measured voltages at the consumer levels. The total harmonic of the supply voltage to the area that were assessed at third, fifth and seventh order are $150 \mathrm{~Hz}, 250 \mathrm{~Hz}$ and $350 \mathrm{~Hz}$ respectively. Table 9 shows the input and output factors of power quality modelling for selected areas in Ado-Ekiti. Table 10 shows power quality model for Ado-Ekiti metropolis using linear regression model. Improvement of the power quality is of paramount importance because the effects and cost of destroying appliances will be vehemently minimized.

ADD TABLES 9\&10

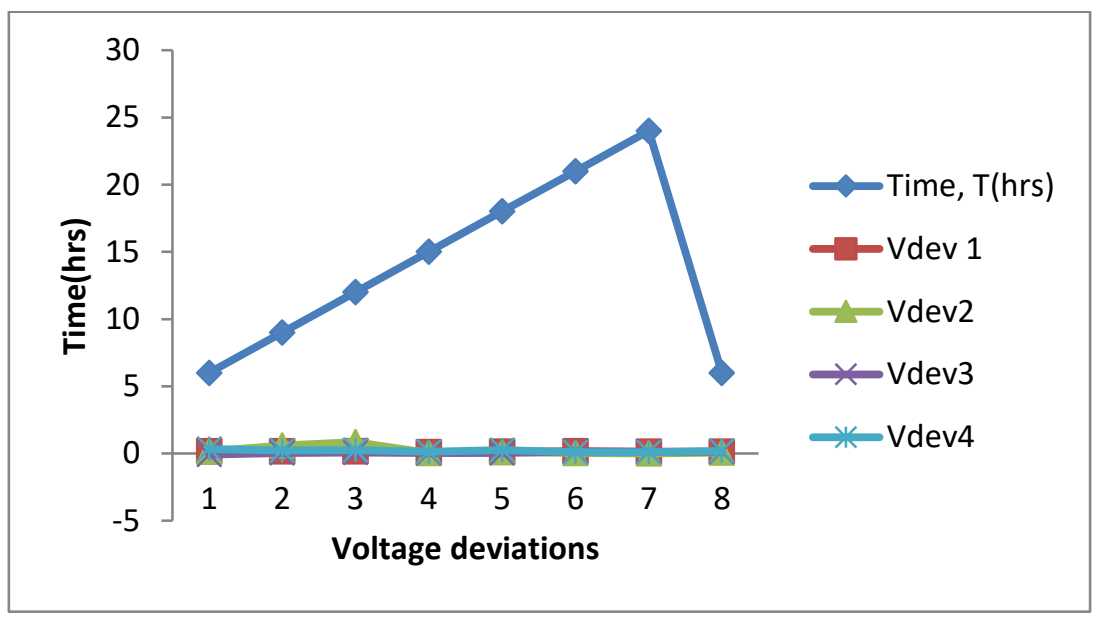

Figure 2: Plot of time against voltage deviations for Ado-Ekiti Metropolis

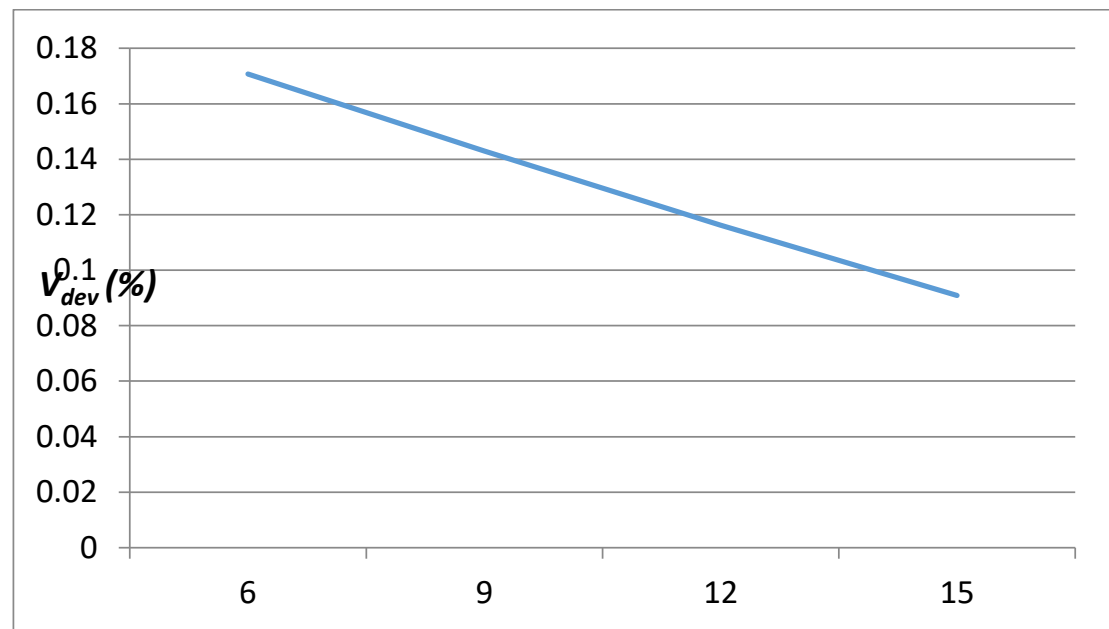

Figure 3: Plot of voltage difference against time from 0 to 15 hours in Ado-Ekiti metropolis 


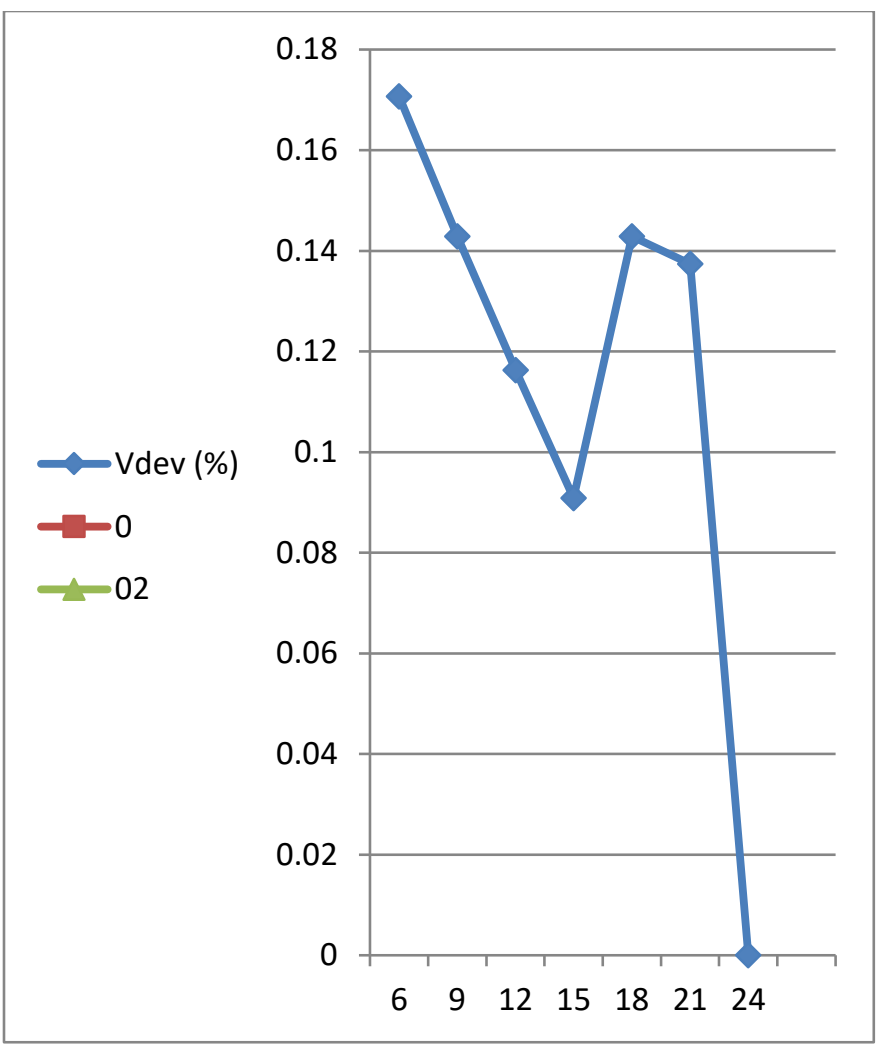

Figure 4: Plot of voltage difference against time from 0 to 24 hours in Ado-Ekiti metropolis

\section{Conclusion}

It has been confirmed that the power quality for three out of the four under consideration in AdoEkiti metropolis from 6-12 hours was not good but fair. It was indeed poor for the fourth area with the use of linear regression model. Effort should be intensified towards using mathematical models to solve the obvious challenges of the hours of 15 to 24. In general, the quality of power supply to Ado-Ekiti metropolis is poor which are characterised by under-voltages, over-voltages, interruptions and outages. Various methods of power quality improvement should be utilized for the areas under consideration. It is of great concern the huge of waste of funds that will be incurred through poor power quality.

\section{Recommendations}

The following points were observed during the course of the research.

1) The voltages that were measured in the areas under consideration were in deviance from the standard of $\pm 6 \%$. .

2) The power quality for areas 1,2, 3 for the hours under consideration were poor with respect to 22 range of above 0.5 but better than that area 4 .

3) The R2 for area 4 was very poor because it was less than 0.5 .

4) All the four areas should be assessed using other mathematical models to address the sinusoidal nature from hour of 15, 18, 21 and 24. 
Table 1: Voltage measurements and estimated deviations for a particular day at intervals

\begin{tabular}{|l|l|l|l|l|l|}
\hline Day & Time (hr) & $\mathbf{U}_{\text {nom }}(\mathbf{V})$ & $\mathbf{U}_{\text {measd }}(\mathbf{V})$ & $\mathbf{U}_{\text {diff }}(\mathbf{V})$ & $\mathbf{U}_{\text {dev }}$ \\
\hline 196 & 6 & 240 & 205 & 35 & 0.1707 \\
\hline 196 & 9 & 240 & 210 & 30 & 0.1429 \\
\hline 196 & 12 & 240 & 225 & 25 & 0.1163 \\
\hline 196 & 15 & 240 & 220 & 20 & 0.909 \\
\hline 196 & 18 & 240 & 210 & 30 & 0.1429 \\
\hline 196 & 21 & 240 & 211 & 29 & 0.1374 \\
\hline 196 & 24 & 240 & 214 & 260 & 0.1215 \\
\hline
\end{tabular}

Table 2: Voltage measurements and estimated deviations for a particular day at intervals

\begin{tabular}{|l|l|l|l|l|l|}
\hline Day & Time (hr) & $\mathbf{U}_{\text {nom }}(\mathbf{V})$ & $\mathbf{U}_{\text {measd }}(\mathbf{V})$ & $\mathbf{U}_{\text {diff }}(\mathbf{V})$ & $\mathbf{U}_{\text {dev }}$ \\
\hline 197 & 6 & 240 & 204 & 36 & 0.1765 \\
\hline 197 & 9 & 240 & 0 & 240 & $\infty$ \\
\hline 197 & 12 & 240 & 0 & 240 & $\infty$ \\
\hline 197 & 15 & 240 & 221 & 19 & 0.086 \\
\hline 197 & 18 & 240 & 214 & 26 & 0.1215 \\
\hline 197 & 21 & 240 & 210 & 30 & 0.1429 \\
\hline 197 & 24 & 240 & 215 & 25 & 0.1163 \\
\hline
\end{tabular}

Table 3: Voltage measurements and estimated deviations for a particular day at intervals

\begin{tabular}{|c|c|c|c|c|c|}
\hline Day & Time (hr) & $\mathbf{U}_{\text {nom }}(\mathbf{V})$ & $\mathbf{U}_{\text {measd }}(\mathbf{V})$ & $\mathbf{U}_{\text {diff }}(\mathbf{V})$ & $\mathbf{U}_{\text {dev }}$ \\
\hline 198 & 6 & 240 & 210 & 30 & 0.1429 \\
\hline 198 & 9 & 240 & 205 & 35 & 0.1717 \\
\hline 198 & 12 & 240 & 209 & 31 & 0.1483 \\
\hline 198 & 15 & 240 & 215 & 25 & 0.1163 \\
\hline 198 & 18 & 240 & 0 & 240 & $\infty$ \\
\hline 198 & 21 & 240 & 0 & 240 & $\infty$ \\
\hline 198 & 24 & 240 & 0 & 240 & $\infty$ \\
\hline
\end{tabular}

Table 4: Voltage measurements and estimated deviations for a particular day at intervals

\begin{tabular}{|c|c|c|c|c|c|}
\hline Day & Time (hr) & $\mathbf{U}_{\text {nom }}(\mathbf{V})$ & $\mathbf{U}_{\text {measd }}(\mathbf{V})$ & $\mathbf{U}_{\text {diff(V) }}$ & $\mathbf{U}_{\text {dev }}$ \\
\hline 199 & 6 & 240 & 206 & 30 & 0.165 \\
\hline 199 & 9 & 240 & 210 & 35 & 0.1483 \\
\hline 199 & 12 & 240 & 199 & 31 & 0.2060 \\
\hline 199 & 15 & 240 & 220 & 25 & 0.0909 \\
\hline 199 & 18 & 240 & 215 & 240 & 0.1163 \\
\hline 199 & 21 & 240 & 203 & 240 & 0.1823 \\
\hline 199 & 24 & 240 & 215 & 240 & 0.1163 \\
\hline
\end{tabular}

Table 5: Voltage measurements and estimated deviations for a particular day at intervals

\begin{tabular}{|c|c|c|c|c|c|}
\hline Day & Time (hr) & $\mathbf{U}_{\text {nom }}(\mathbf{V})$ & $\mathbf{U}_{\text {measd }}(\mathbf{V})$ & $\mathbf{U}_{\text {diff }}(\mathbf{V})$ & $\mathbf{U}_{\text {dev }}$ \\
\hline 200 & 6 & 240 & 203 & 37 & 0.165 \\
\hline 200 & 9 & 240 & 207 & 33 & 0.1594 \\
\hline
\end{tabular}




\begin{tabular}{|c|c|c|c|c|c|}
\hline 200 & 12 & 240 & 0 & 240 & 0.2060 \\
\hline 200 & 15 & 240 & 0 & 240 & 0.0909 \\
\hline 200 & 18 & 240 & 210 & 30 & 0.1163 \\
\hline 200 & 21 & 240 & 211 & 29 & 0.1823 \\
\hline 200 & 24 & 240 & 215 & 25 & 0.1163 \\
\hline
\end{tabular}

Table 6: Voltage measurements and estimated deviations for a particular day at intervals

\begin{tabular}{|c|c|c|c|c|c|}
\hline Day & Time (hr) & $\mathbf{U}_{\text {nom }}(\mathbf{V})$ & $\mathbf{U}_{\text {measd }}(\mathbf{V})$ & $\mathbf{U}_{\text {diff }}(\mathbf{V})$ & $\mathbf{U}_{\text {dev }}$ \\
\hline 201 & 6 & 240 & 210 & 30 & 0.1429 \\
\hline 201 & 9 & 240 & 215 & 25 & 0.1163 \\
\hline 201 & 12 & 240 & 0 & 240 & $\infty$ \\
\hline 201 & 15 & 240 & 0 & 240 & $\infty$ \\
\hline 201 & 18 & 240 & 210 & 30 & 0.1429 \\
\hline 201 & 21 & 240 & 205 & 35 & 0.1707 \\
\hline 201 & 24 & 240 & 200 & 40 & 0.02 \\
\hline
\end{tabular}

Table 7: Voltage measurements and estimated deviations for a particular day at intervals

\begin{tabular}{|c|c|c|c|c|c|}
\hline Day & Time (hr) & $\mathbf{U n o m}_{\text {nom }}$ & $\mathbf{U}_{\text {measd }}(\mathbf{V})$ & $\mathbf{U}_{\text {diff }}(\mathbf{V})$ & $\mathbf{U}_{\text {dev }}$ \\
\hline 202 & 6 & 240 & 0 & 240 & $\infty$ \\
\hline 202 & 9 & 240 & 0 & 240 & $\infty$ \\
\hline 202 & 12 & 240 & 0 & 240 & $\infty$ \\
\hline 202 & 15 & 240 & 0 & 240 & $\infty$ \\
\hline 202 & 18 & 240 & 0 & 240 & $\infty$ \\
\hline 202 & 21 & 240 & 210 & 30 & 0.1429 \\
\hline 202 & 24 & 240 & 215 & 25 & 0.1163 \\
\hline
\end{tabular}

Table 8: Voltage measurements and estimated deviations for a particular day at intervals

\begin{tabular}{|c|c|c|c|c|c|}
\hline Day & Time (hr) & $\mathbf{U}_{\text {nom(V) }}$ & $\mathbf{U}_{\text {measd }}(\mathbf{V})$ & $\mathbf{U}_{\text {diff }}(\mathbf{V})$ & $\mathbf{U}_{\text {dev }}$ \\
\hline 203 & 6 & 240 & 210 & 30 & 0.1429 \\
\hline 203 & 9 & 240 & 0 & 240 & $\infty$ \\
\hline 203 & 12 & 240 & 215 & 25 & 0.1163 \\
\hline 203 & 15 & 240 & 0 & 240 & $\infty$ \\
\hline 203 & 18 & 240 & 0 & 240 & $\infty$ \\
\hline 203 & 21 & 240 & 210 & 30 & 0.1429 \\
\hline 203 & 24 & 240 & 222 & 18 & 0.0811 \\
\hline
\end{tabular}

Table 9: Inputs and output factors of Power quality modelling in selected areas in Ado-Ekiti

\begin{tabular}{|c|c|c|}
\hline D & T & $\mathbf{V}$ \\
\hline 196 & 6 & 0.1707 \\
\hline 197 & 9 & 0.1594 (VALUE FOR DAY200) \\
\hline 198 & 12 & 0.1483 \\
\hline 199 & 15 & 0.0909 \\
\hline 200 & 18 & 0.1429 (VALUE FOR DAY 201) \\
\hline 201 & 21 & 0.1707 \\
\hline
\end{tabular}




\begin{tabular}{|c|c|c|}
\hline 202 & 24 & 0.1163 \\
\hline 203 & 6 & 0.1429 \\
\hline
\end{tabular}

Table 10: Power Quality Modelling for Ado-Ekiti Metropolis using linear regression model

\begin{tabular}{|c|c|c|c|c|c|}
\hline Day, D & Time, T (hrs) & $\mathbf{V}_{\text {dev 1 }}$ & $\mathbf{V}_{\text {dev2 }}$ & $\mathbf{V}_{\text {dev3 }}$ & $\mathbf{V}_{\text {dev4 }}$ \\
\hline 196 & 6 & 0.1707 & 0.1707 & -0.083 & 0.3333 \\
\hline 197 & 9 & 0.1594 & 0.6 & 0.0213 & 0.2308 \\
\hline 198 & 12 & 0.1483 & 0.8462 & 0.0573 & 0.2632 \\
\hline 199 & 15 & 0.0909 & 0.0434 & 0.0213 & 0.1163 \\
\hline 200 & 18 & 0.1429 & 0.0909 & 0.0345 & 0.2632 \\
\hline 201 & 21 & 0.1707 & 0.0435 & 0.1538 & 0.1009 \\
\hline 202 & 24 & 0.1163 & 0 & 0.1163 & 0.0909 \\
\hline 203 & 6 & 0.1429 & 0.0667 & 0.1429 & 0.2 \\
\hline
\end{tabular}

Table 11: Processed data output of voltage deviation from 0 to 24 hours

\begin{tabular}{|c|c|c|c|c|c|c|c|c|}
\hline \multicolumn{9}{|l|}{$\begin{array}{l}\text { SUMMARY } \\
\text { OUTPUT }\end{array}$} \\
\hline \multicolumn{9}{|c|}{ Regression Statistics } \\
\hline Multiple R & $\begin{array}{l}0.9114 \\
301 \\
86\end{array}$ & & & & & & & \\
\hline R Square & $\begin{array}{l}0.8307 \\
04984\end{array}$ & & & & & & & \\
\hline $\begin{array}{ll}\text { Adjusted } & \mathrm{R} \\
\text { Square } & \end{array}$ & $\begin{array}{l}0.2460 \\
57477\end{array}$ & & & & & & & \\
\hline $\begin{array}{l}\text { Standard } \\
\text { Error }\end{array}$ & $\begin{array}{l}0.0178 \\
80366\end{array}$ & & & & & & & \\
\hline Observations & 4 & & & & & & & \\
\hline \multicolumn{9}{|l|}{ ANOVA } \\
\hline & $D f$ & $S S$ & $M S$ & $F$ & $\begin{array}{l}\text { Signific } \\
\text { ance } F\end{array}$ & & & \\
\hline Regression & 2 & $\begin{array}{l}0.00313 \\
8\end{array}$ & $\begin{array}{l}0.001 \\
569\end{array}$ & $\begin{array}{l}9.813 \\
697\end{array}$ & 0.22018 & & & \\
\hline Residual & 2 & $\begin{array}{l}0.00063 \\
9\end{array}$ & $\begin{array}{l}0.000 \\
32\end{array}$ & & & & & \\
\hline \multirow[t]{2}{*}{ Total } & 4 & $\begin{array}{l}0.00377 \\
7\end{array}$ & & & & & & \\
\hline & $\begin{array}{l}\text { Coeffici } \\
\text { ents }\end{array}$ & $\begin{array}{l}\text { Standard } \\
\text { Error }\end{array}$ & $t$ Stat & $\begin{array}{l}P \text { - } \\
\text { value }\end{array}$ & $\begin{array}{l}\text { Lower } \\
95 \%\end{array}$ & $\begin{array}{l}\text { Upper } \\
95 \%\end{array}$ & $\begin{array}{l}\text { Lower } \\
95.0 \%\end{array}$ & $\begin{array}{l}\text { Upper } \\
95.0 \%\end{array}$ \\
\hline Intercept & 0.23 & 0.02938 & $\begin{array}{l}7.828 \\
338\end{array}$ & $\begin{array}{l}0.015 \\
929\end{array}$ & $\begin{array}{l}0.10358 \\
6\end{array}$ & $\begin{array}{l}0.3564 \\
14\end{array}$ & $\begin{array}{l}0.10358 \\
6\end{array}$ & $\begin{array}{l}0.35641 \\
4\end{array}$ \\
\hline
\end{tabular}




\begin{tabular}{|l|l|l|l|l|l|l|l|l|l|}
\hline X Variable 1 & 0 & 0 & $\begin{array}{l}6553 \\
5\end{array}$ & $\begin{array}{l}\text { \#NU } \\
\text { M! }\end{array}$ & 0 & 0 & 0 & 0 \\
\hline X Variable 2 & - & 0.00266 & - & 0.088 & - & 0.0031 & - & 0.00311 \\
& $\begin{array}{l}0.0083 \\
5\end{array}$ & 5 & $\begin{array}{l}3.132 \\
68\end{array}$ & 0.01982 & 18 & 0.01982 & 8 \\
\hline
\end{tabular}

Table 12: Processed data output of voltage deviation from 0 to 24 hours

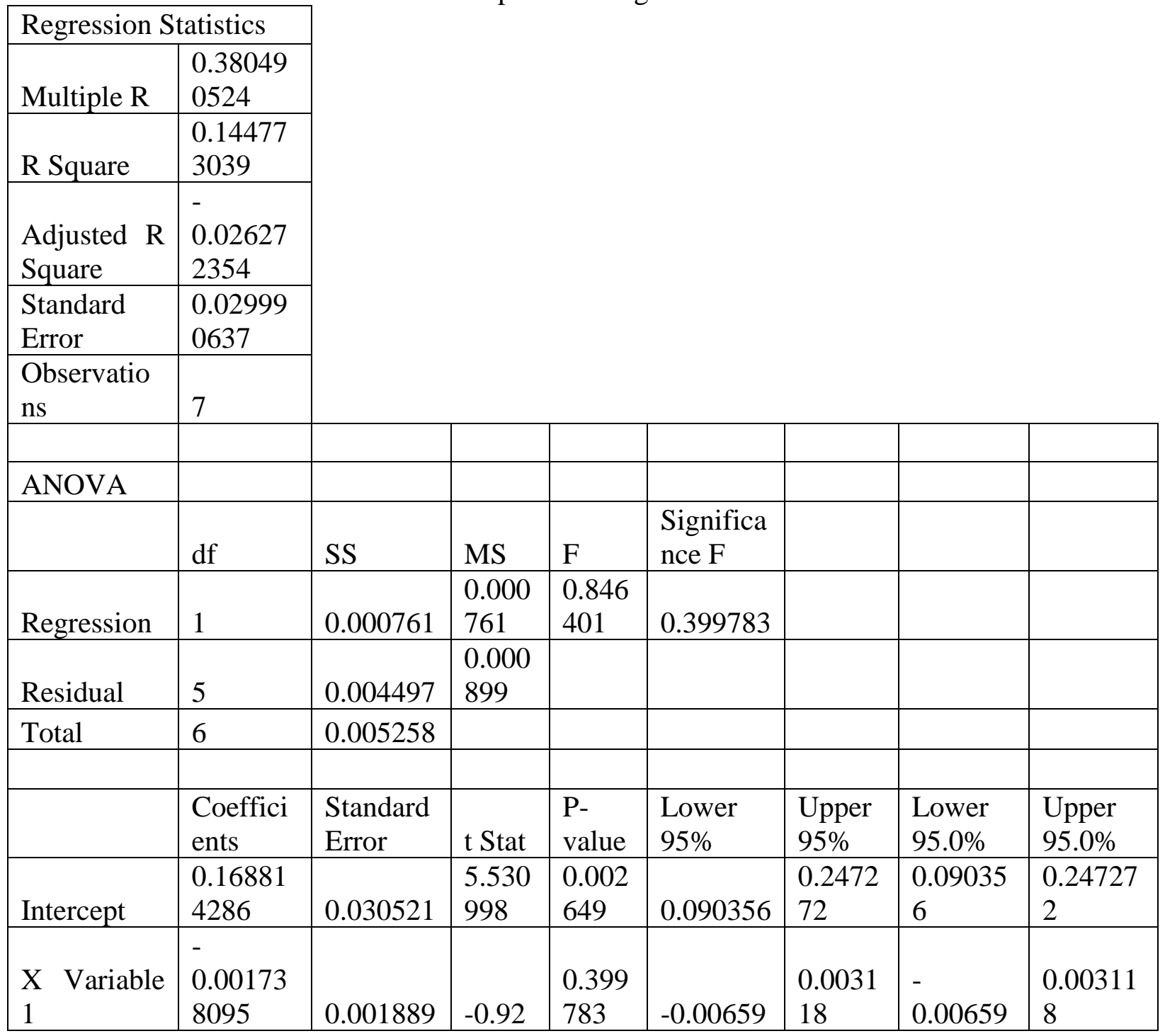

\section{References}

[1] Mehta V.K and Mehta R (2008): 'Principles of Power System', S.Chand and Company Limited, Ram Nagar, New Delhi-110055:, 2008, pp1-577

[2] Kholiddinov, I.K: 'Electric Power Quality Analysis', Energy and Power Engineeering, Vol. 8, issue 6, 10.4236/epe.86025, 2016, pp 263-269.

[3] Gupta, J.B: 'Power System Analysis and Design', S. Chand and Company, Ram Nagar, New Delhi110055, 2008, pp 1-610. 
[4] Lepka :'Managing power quality challenges' retrieved from www.electricenergyonline.com,2005, on 22nd October, 2016.

[5] Daniel, O.J and Kabiru, A.H:'Issues of Power Quality in Electrical Systems'. International Journal of Energy and PowerEngineering.2016,5(4),pp148-154. Doi11648/j.ijepe.2016,5(4).

[6] Mahesh. A. P, Ankit. R.P, Dhaval. R. Vand Ketul. M. P: 'Use of PWM Techniques for Power Quality improvement', International Journal of Recent TrendsinEngineeering, 2009, 1(4), pp 99102.

[7] Sankanran, C: 'Power Quality', CRC Press LLC, 2000 N.W.Corporate Blvd, Boca Raton, Florida, 33431, 2002, pp 1-202.

[8] Schipman and Delince: 'The importance of good Power Quality', ABB Power Quality Products, Belgium.retrievedfrom http://ablibrary.s3amazonaws.com on 5th August,2016, pp 1-20.

[9] Sivakoti K.K, Kumar N and Archana. D: 'Power Quality improvement in Distribution System using D-Statcom in Transmission Lines', International Journal of Engineering Research and Applications, Vol. 1, issue 3, retrieved from hhp://www.ijera.com on 6thAugust,2016, pp 748-752.

[10] Sharmistha, B and Sjef, C: 'Consequence of Poor Power Quality - Overview', Technical University of Eindhoven, Netherlands, 2011, pp 1-23.

[11] Belloni, R, Chiumeo, R, Gandolfi, C, and Villa, A: 'A Series Compensation Device for the LV Power Quality Improvement. International Conference on Renewable Energies and Power Quality, Malaga, Spain, Vol. 1, issue 15, https://doi.org/10.24084/repqj15.220,4th - 6th April, 2017.

[12] Barry, W. K: 'Power Quality Primer, McGraw Hill Companies Incorporation', 2000.

[13] Adeoye, O.S: 'Assessment of primary distribution network capacity for rural electrification in Ekiti State', Federal University of Technology, Akure, 2010, pp 1-38.

[14] Esasd: 'Case study in service quality regulation in Nigeria', 2016, pp 1-15.

*Corresponding author.

E-mail address: Paulade001@ yahoo.com 